\title{
Study the Effect of Indium on the Urbach Energy and Dispersion Parameters of CdO Thin Films
}

\author{
Tahseen H. Mubarak ${ }^{100}$ Sami Salman Chiad ${ }^{2 *}$ Mahmood M. Kareem $^{3}$ Nadir Fadhil \\ Habubi $^{2 \#}$ Mohamed Odda Dawod $^{4 \sim}$ Ehssan S. Hassan ${ }^{4 \wedge}$ \\ ${ }^{1}$ Department of Physics, College of Science, University of Diyala, Diyala, Iraq ${ }^{2}$ Department of Physics, \\ College of Education, Mustansiriyah University, Baghdad, Iraq \\ *Email: dr.sami@uomustansiriyah.edu.iq \\ \#nadirfadhil@uomustansiriyah.edu.iq \\ ${ }^{3}$ Department of Physics, College of Education, University of Garmian, Kalar, Iraq \\ Email: mahmood.mohammed@garmian.edu.krd \\ ${ }^{4}$ Department of Physics, College of Science, Mustansiriyah University, Baghdad, Iraq \\ Email: mohammedodda2017@uomustansirivah.edu.iq \\ ^Email: ehsanphysicyan@uomustansiryah.edu.iq \\ ${ }^{\infty}$ Corresponding author. Email: dean@sciences.uodiyala.edu.iq
}

\begin{abstract}
CdO thin films have been deposited onto glass substrate by chemical spray pyrolysis. Transmittance and reflectance spectra in the range300-900 nm were recorded via UVVisible spectrophotometer for various In-content in the CdO:In thin films. Transmittance decreased with increasingIn-content in the CdO:In thin films, while the reflectance slightly increased in the wavelength more than $480 \mathrm{~nm}$. Urbach energy decreased with increasing In-content in the CdO:In thin films. Dispersion parameters are calculated, and find that $\mathrm{E}_{\mathrm{d}}, \mathrm{E}_{\mathrm{o}}, \varepsilon_{\infty}, \mathrm{n}(0), \mathrm{S}_{\mathrm{o}}, \mathrm{M}_{-1}$ and $\mathrm{M}_{-3}$ are increased with increasing Incontent in the CdO:In thin films.
\end{abstract}

Keywords: Thin films, Cdo:In, Spray pyrolysis, reflectance, Dispersion,

\section{Introduction}

Transparent conducting oxide (TCO) thin films have great importance in electronic device applications and among these TCOs, cadmium oxide (CdO), an n-type semiconductor with band gap of $2.5 \mathrm{eV}$ [1].

Inthethinfilmform,itfindsapplicationsingassensordevices,photodiodes, transparentelectrod es, phototransistors and solar cells[2]. 
Various techniques have been employed to prepare $\mathrm{CdO}$ thin films such as spray pyrolysis [3], sputtering [4,5], solution growth [6], activated reactive evaporation [7], pulsed laser deposition [8] and sol-gel method [9].

Urbach energy and dispersion parameters of $\mathrm{CuO}$ thin films were calculated and study the effect of In contenton these films.

\section{Experimental Part}

$0.1 \mathrm{M}$ of $\mathrm{Cd}\left(\mathrm{CooCH}_{3}\right)_{2}$ (supplied from Sigma-Aldrich Chemicals) dissolve in re-distilled water and an aqueous solution of $0.1 \mathrm{M}$ of $\mathrm{InCl}_{3}(2 \%$ and $4 \%$ volume) (supplied from Sigma-Aldrich Chemicals) were used as precursormaterials to obtain the deposited films by chemical spray pyrolysis on to glass substrate. The optimum conditions were arrived at the following parameters:Substrate temperature was kept at $350{ }^{\circ} \mathrm{C}$ during deposition process, the distance between nozzle and substrate was $28 \mathrm{~cm}$, compressed air was used as a carrier gas , and rate of depositon was $2 \mathrm{ml} / \mathrm{min}$. Thickness wasobtained bygravimetricmethod was about $350 \mathrm{~nm}$. Double beam UV-Visible spectrophotometer was used in order to record the absorbance spectra and calculate the optical parameters..

\section{Results and Discussion:}

The obtained results measured that recorded from UV-Visible spectrophotometer is plotted in Fig. 1 for In-doped CdO thin films prepared by chemical spray pyrolysis. From this figure, it can notice the decreases of transmittance with increasing In-doping in the $\mathrm{CdO}$ thin films, and also decreased with decreasing wavelength (at high photon energy, the absorbance of films increases leads to decreasing transmittance). 


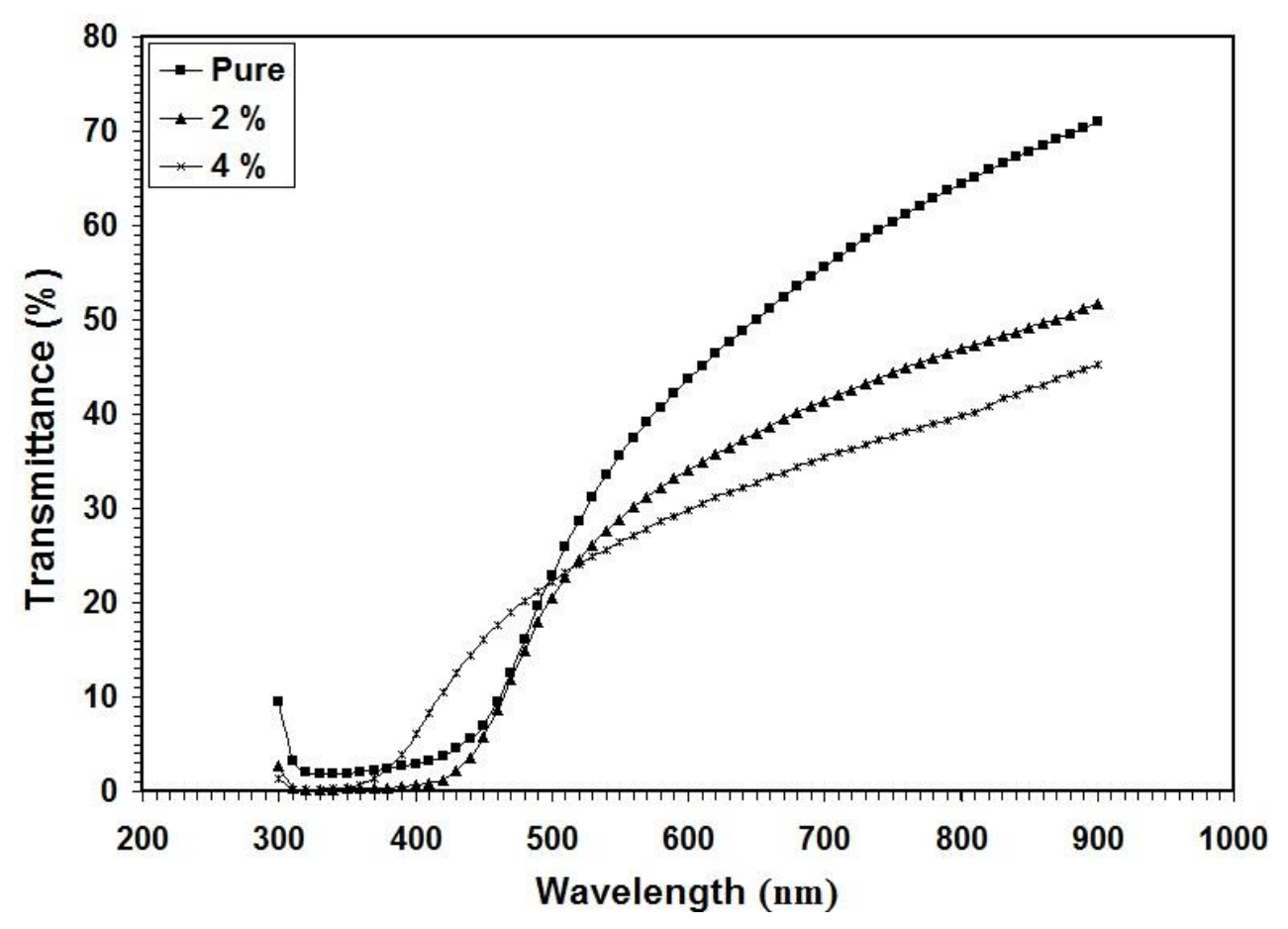

Fig.1: Transmittance spectra of CdO:In thin films with various In-doping.

The reflectance $(\mathrm{R})$ has been found by using the relationship:

$$
\mathrm{R}+\mathrm{T}+\mathrm{A}=1
$$

where $\mathrm{T}$ and $\mathrm{A}$ is the transmittance and absorbance respectively. The reflectance spectra versus wavelength was plotted in Fig. 2. The reflectance increased slightly with increasing In-doping at wavelength more than $480 \mathrm{~nm}$.

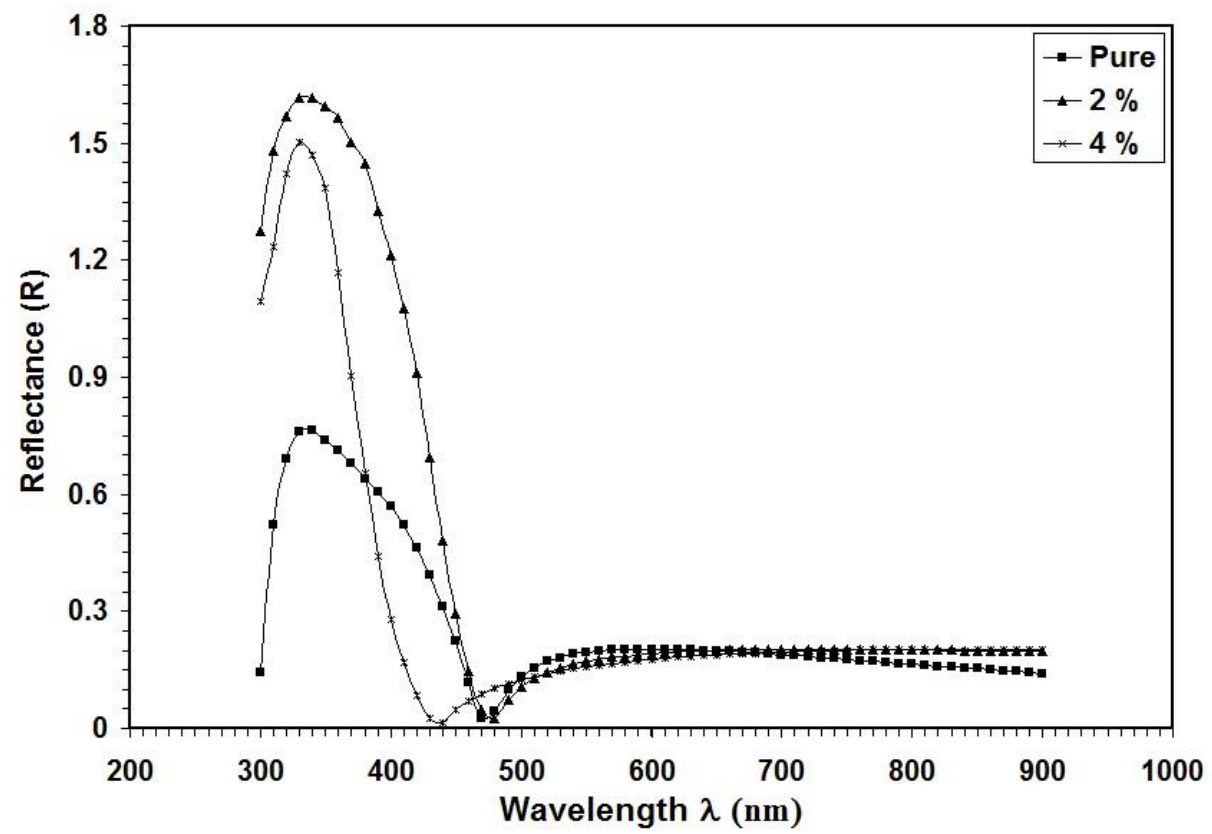


Fig.2: Reflectance spectra of CdO:In thin films with various In-doping.

The optical conductivity was calculated using the relation [10]:

$\mathrm{Q}=\frac{\alpha \mathrm{nc}}{4 \pi} \quad \ldots$

where $\alpha$ is absorption coefficient, $\mathrm{n}$ is refractive index, and $\mathrm{c}$ is speed of light. The optical conductivity as a function of wavelength was plotted in Fig.3. From this figure, it can notice the slight decreases with increasing In-doping at wavelength more than 480 $\mathrm{nm}$ for pure and In-doped $\mathrm{CdO}$ thin films.

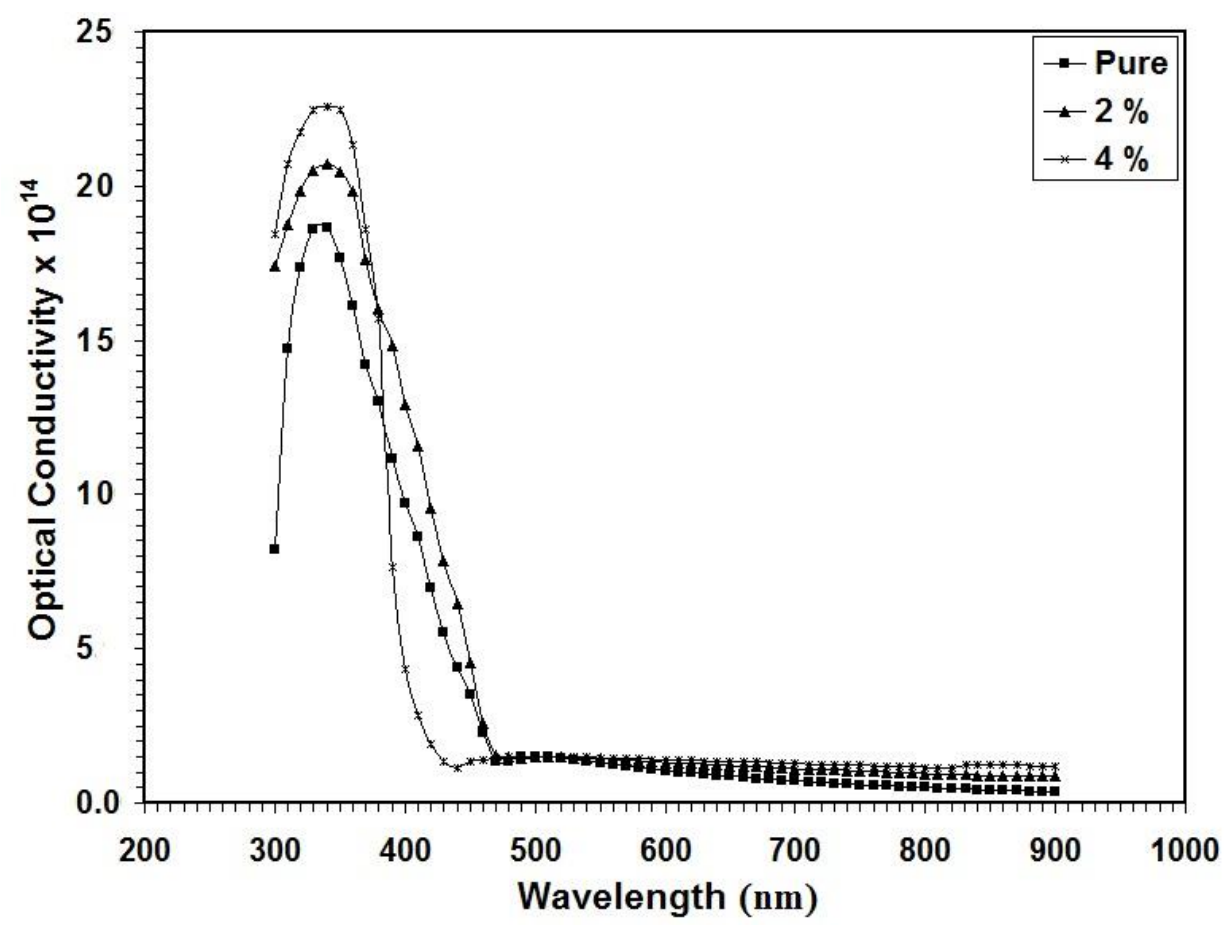

Fig.3: Optical conductivity of CdO:In thin films with various In-doping.

The absorption edge gives a measure of the energy band gap and the exponentialdependence of the absorption coefficient, in the exponential edge region Urbach rule is expressed as[11]:

$\alpha=\alpha_{\mathrm{o}} \exp \left(\frac{\mathrm{h} v}{\mathrm{E}_{\mathrm{U}}}\right) \quad \ldots$

where $\alpha_{\circ}$ is aconstant, $E_{U}$ is the Urbach energy, which characterizes the slope of the exponential edge. The values of $\mathrm{E}_{\mathrm{U}}$ are obtained from plotting relation between $\ln \alpha$ versus photon energy (hv) as in Fig. 4, the slope value represent the Urbachenergy. 
These values are listed in Table 1.The absorption in this region is due to the transitions between the extended states in one band and the localized statesin the exponential tail of the other band. From the Table, the Urbach energy decreased with increasing In-content in $\mathrm{CdO}$ thin films.

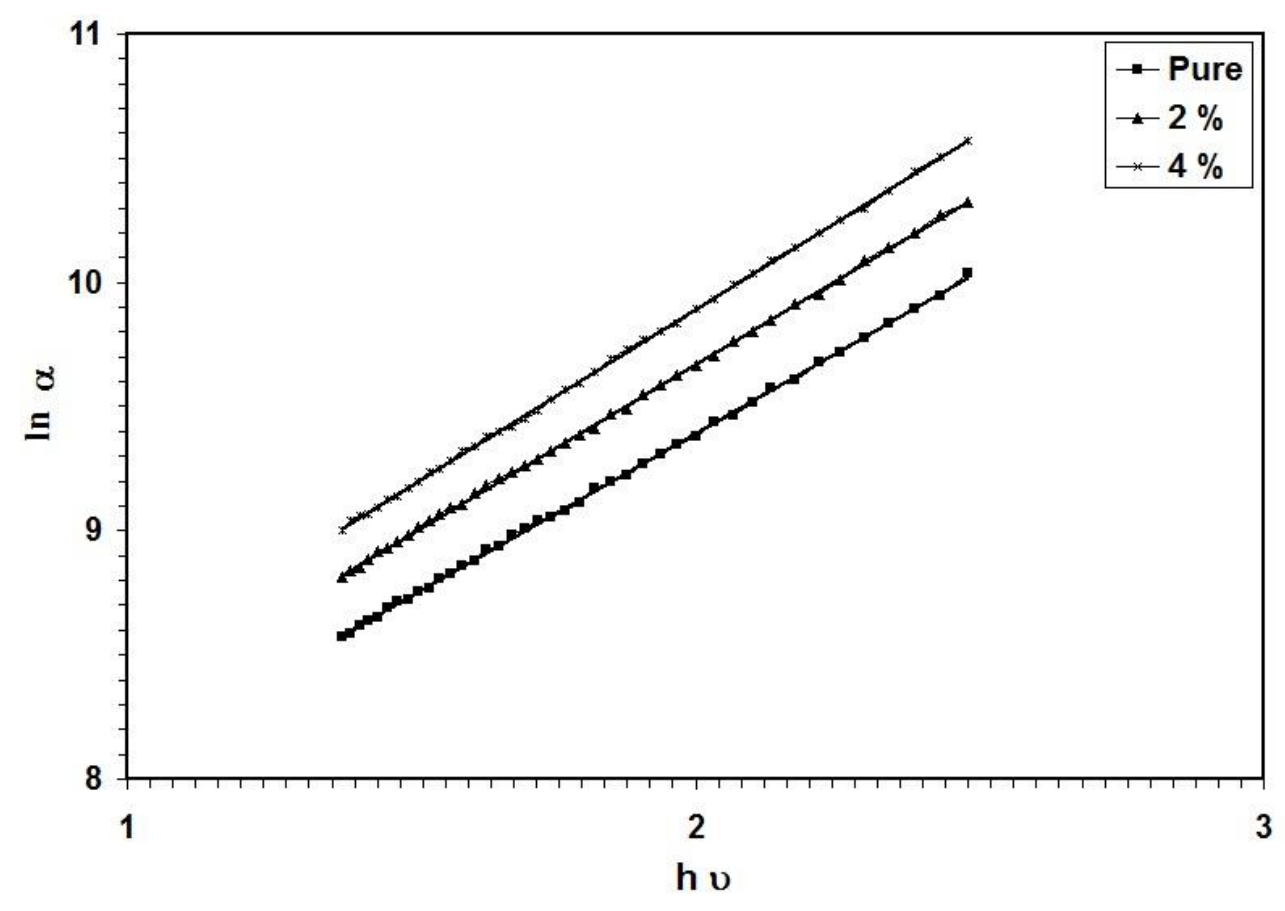

Fig.4: Lna versus hv of CdO:In thin films with various In-doping.

The refractive index dispersion for crystallized and amorphousmaterials can be expressed as [12]:

$n^{2}-1=\frac{E_{o} E_{d}}{E_{o}^{2}-E^{2}}$

Where $\mathrm{n}$ is the real part of refractive index, hv is the photon energy, $\mathrm{E}_{\mathrm{o}}$ is the average excitation energy for electronictransitions and $E_{d}$ is the dispersion energy, which is ameasure of the strength of interband optical transitions. This model describes the dielectric response for transitionsbelow the optical gap.

By plotting $\left(\mathrm{n}^{2}-1\right)^{-1}$ vs. $(\mathrm{hv})^{2}$ and fittinga straight line, the values of the parameters $\mathrm{E}_{\mathrm{o}}$ and $E_{d}$ were calculated from $\left(E_{0} / E_{d}\right)$ represents the intercept onthe vertical axis and $\left(E_{0} E_{d}\right)^{-}$ ${ }^{1}$ is the slope of the plot, this shown in Fig. 5. 


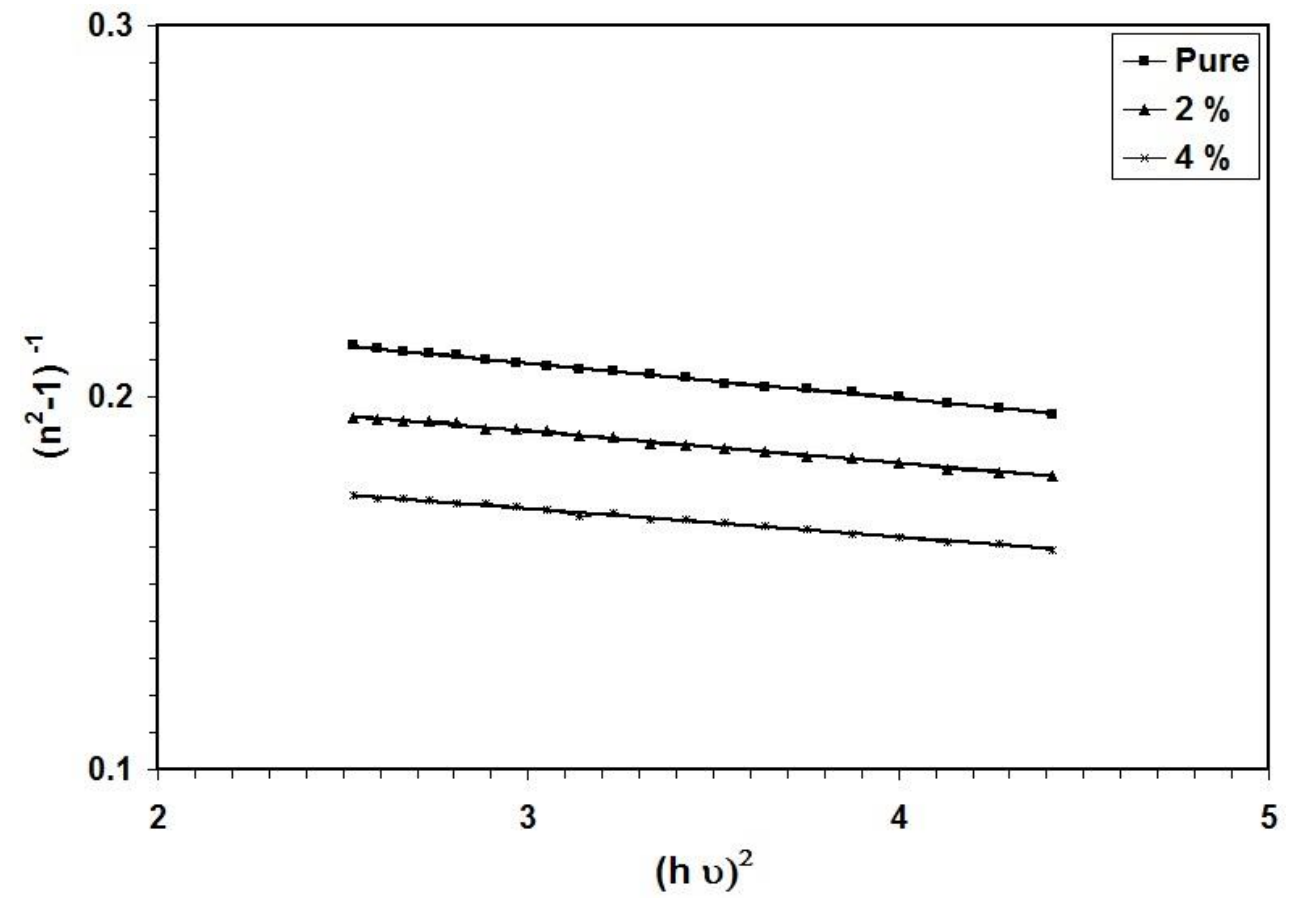

Fig.5: $\left(\mathrm{n}^{2}-1\right)^{-1}$ versus $(\mathrm{hv})^{2}$ of CdO:In thin films with various In-doping.

The refractive index at infinite wavelength $\left(\mathrm{n}_{\infty}\right)$ can be determined from the following relation [13]:

$\frac{\mathrm{n}_{\infty}^{2}-1}{\mathrm{n}^{2}-1}=1-\left(\frac{\lambda_{\mathrm{o}}}{\lambda}\right)^{2}$

The plot of $\left(n^{2}-1\right)^{-1}$ versus $\lambda^{-2}$ was plotted to find the values of $\left(n_{\infty}\right)$ of CdO:In thin films. These values are shown in Table 1 . 


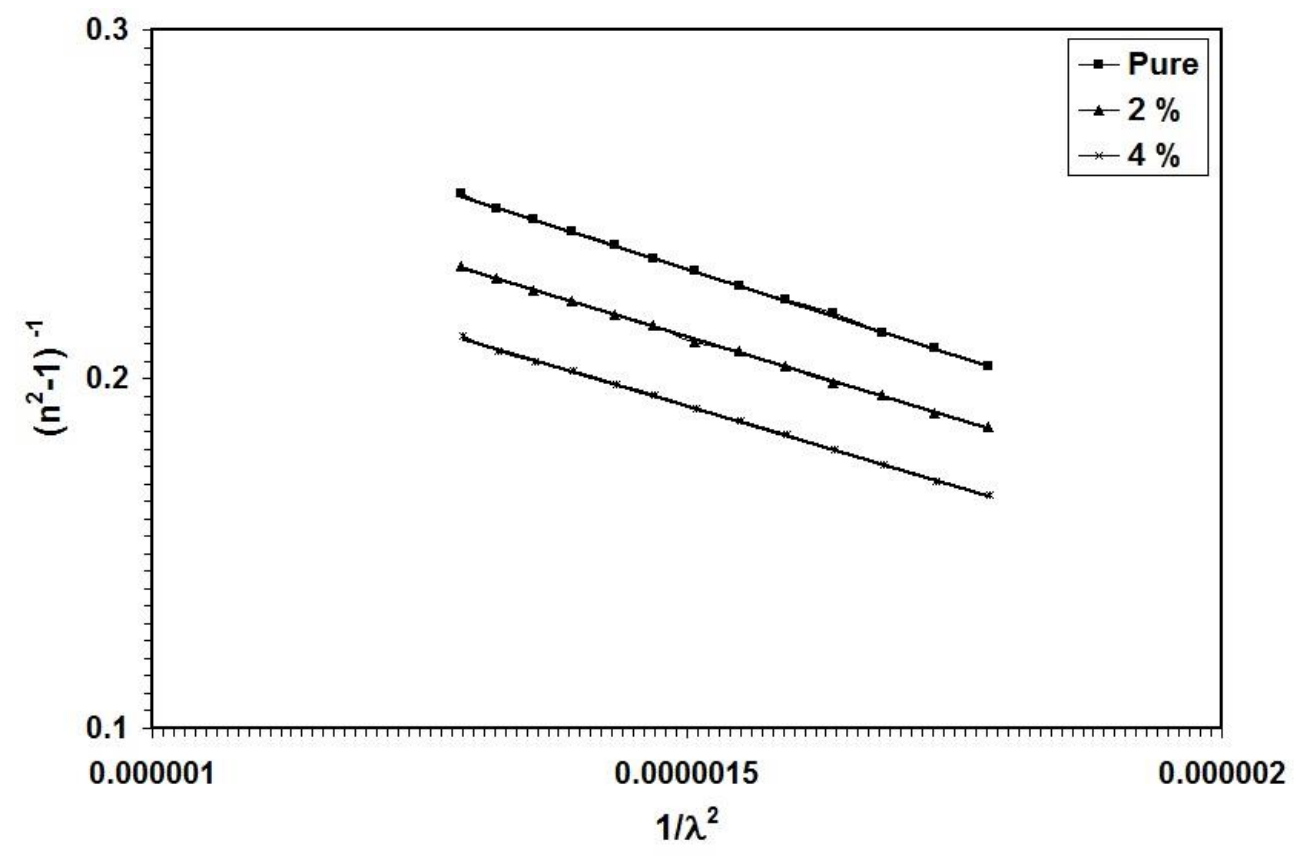

Fig.6: $\left(n^{2}-1\right)^{-1}$ versus $1 / \lambda^{2}$ of $\mathrm{CdO}$ :In thin films with various In-doping.

The $\mathrm{M}_{-1}$ and $\mathrm{M}_{-3}$ moments of the optical spectra have obtained from the following relations [14]:

$\mathrm{E}_{\mathrm{d}}^{2}=\frac{\mathrm{M}_{-1}^{3}}{\mathrm{M}_{-3}} \quad$ and $\quad \mathrm{E}_{\mathrm{o}}^{2}=\frac{\mathrm{M}_{-1}}{\mathrm{M}_{-3}}$

The values of $M_{-1}$ and $M_{-3}$ moments of the optical spectra are increased with increasing In-content in the CdO:In thin films as shown in Table 1.

Table 1: Some optical parameters of CdO:In thin films.

\begin{tabular}{|l|l|l|l|l|l|l|l|l|l|l|}
\hline Sample & $\begin{array}{l}\mathrm{E}_{\mathrm{d}} \\
(\mathrm{eV})\end{array}$ & $\begin{array}{l}\mathrm{E}_{\mathrm{o}} \\
(\mathrm{eV})\end{array}$ & $\begin{array}{l}\mathrm{E}_{\mathrm{g}} \\
(\mathrm{eV})\end{array}$ & $\varepsilon_{\infty}$ & $\mathrm{n}(\mathrm{o})$ & $\mathrm{M}_{-1}$ & $\begin{array}{l}\mathrm{M}_{-3} \\
\mathrm{eV}^{-2}\end{array}$ & $\begin{array}{l}\mathrm{S}_{\mathrm{o}} \times 10^{13} \\
\mathbf{m}^{-2}\end{array}$ & $\begin{array}{l}\lambda_{\mathrm{o}} \\
\mathrm{nm}\end{array}$ & $\begin{array}{l}\mathrm{U}_{\mathrm{E}} \mathrm{m} \\
\mathrm{eV}\end{array}$ \\
\hline Pure & 21.87 & 4.81 & 2.406 & 5.545 & 2.35 & 4.54 & 0.196 & 1.01 & 592 & 769 \\
\hline $2 \%$ & 24.25 & 4.85 & 2.425 & 6.000 & 2.45 & 5.00 & 0.212 & 1.07 & 599 & 740 \\
\hline $4 \%$ & 27.47 & 5.03 & 2.517 & 6.560 & 2.56 & 5.50 & 0.219 & 1.10 & 615 & 704 \\
\hline
\end{tabular}

\section{Conclusions}

$\mathrm{CdO}$ thin films with various amounts of In-content have been deposited onto glass substrate by chemical spray pyrolysis. Transmittance spectra in the range of 300-900 nm decreased with increasingIn-content in the CdO:In thin films. Urbach energy decreased 
with increasing In-content in the CdO:In thin films, while the energy gap increased from $2.406 \mathrm{eV}$ to $2.517 \mathrm{eV}$ after additive of $4 \% \mathrm{In}$ in the CdO:In thin films. Dispersion parameters such as: $E_{d}, E_{0}, \varepsilon_{\infty}, n(0), S_{0}, \lambda_{0}, M_{-1}$ and $M_{-3}$ are decreased with increasing Incontain in the CdO:In thin films.

\section{References}

[1] N.Manjula,K.Usharani,A.R.Balu, V.S.Nagarethinam, Studies on the physical properties of three potentially important TCO thin films fabricated by a simplified spray technique and a same deposition conditions Int. J.chemTech. Res.6, 705-718, (2014).

[2] C. Sravani,K.T.R. Reddy, O.Md. Hussain,P.J. Reddy,J.SolarEnergySoc.

India 6, 1 (1996).

[3] M. D. Uplane, P. N. Kshirsagan, B. J. Lokhande, C. H. Bhosale, Materials Chemistry and Physics, p.64, 75, (2000).

[4]T. K. Subramanyam, S. Uthanna, B. Sinivasulu Naidu, Materials Letters 35 (1998) 214, and Appl. Surface Science, p.169,529, (2001).

[5] K. Gurumurugan, D. Mangalaraj, Sa. K. Narayandass, J. Electron. Mater, p.25, 765, (1996). |

[6] A. J. Varkey, A. F. Fort, (Thin Solid Films )pp:239, 211(1994).|

[7] K. T. Ramakrishna Reddy, C. Sravani, R. W. Miles, J. Cryst. Growth p. 184/185, 1031, (1998). |

[8] Xiaonan Li, Timothy Gessert, Clay DeHart, Teresa Barnes, ( A Comparison of Composite Transparent Conducting Oxides Based on the Binary Compounds $\mathrm{CdO}$ and $\mathrm{SnO}_{2}$ ) National Renewable Energy Laboratory 14-17 October (2001).

[9] D. M. Carballeda-Galicia, R. Castanedo-Perez, O. Jimenez-Sandoval, S. JimenezSandoval, G. Torres-Delgado, C.I. Zuniga-Romero, (Thin Solid Films), p: 371,105 ,(2000).

[10] J. I. Pankove, “Optical processes in semiconductors”, Dover Publications, Inc. New York, pp. 91, (1975).

[18]J. Tauc,“Amorphous and Liquid Semiconductors”, Plenum Press, New York, 1974. 
[11] M. DiDomenico and S.H. Wemple, "Oxygen-octahedra ferroelectrics. I. theory of electro-optical and nonlinear optical effects”, J. Appl. Phys.40, 720 (1969)

[12] F. Yakuphanoglu and C. Viswanathan, "Electrical conductivity and single oscillator model properties of amorphous CuSe semiconductor thin film", Journal of Noncrystalline Solids, Vol. 353, pp. 2934-2937, (2007).

[13] S.H. Wemple, M. DiDomenico, "Optical Dispersion and the Structure of solid", Phys. Rev. Litt. 23, 20, 1156-1160, (1969). 